\title{
Review on Potential of Reproductive Technology to Improved Ruminant Production in Ethiopia
}

\author{
Jalel Fikadu Yadeta \\ Assosa University, College of Agriculture and Natural Resources, Department of animal science, Assosa, \\ Ethiopia
}

DOI: $10.7176 / \mathrm{JBAH} / 10-8-02$

Publication date: April $30^{\text {th }} 2020$

\section{INTRODUCTION}

Reproductive technology encompasses all current and anticipated uses of technology in human and animal reproduction, including assisted reproductive technology, contraception and others (Mapletoft and Hasler, 2005). Research into physiology and embryology has provided a basis for the development of technologies that increase productivity of farm animals through enhanced control of reproductive function. Animal Biotechnology represents an expanding collection of rapidly developing disciplines in science and information technologies. The livestock provides many opportunities to utilize these disciplines and evolving competencies. Individually, these are powerful tools capable of providing significant improvements in productivity. Combinations of these technologies coupled with information systems and data analysis will provide even more significant changes in the next decade.

Various techniques have been developed and refined to obtain a large number of offspring from genetically superior animals or obtain offspring from infertile (or sub fertile) animals (Naqvi et al., 2001; Blackburn, 2004). Based on the progress in scientific knowledge of endocrinology, reproductive physiology, cell biology and embryology during the last fifty years new bio techniques have been developed for and introduced into animal breeding and husbandry (Wrathall et al., 2004). Among them are estrus synchronization/induction, artificial insemination, Multiple Ovulation Induction and Embryo Transfer (MOET), in vitro embryo production (IVP) and cloning by Nuclear Transfer (NT) all are components of the tool box for present and future applications (Betteridge, 2003). Techniques are now available to get genetically improved farm animals in large numbers. This involves collection of the fertilized egg from genetically superior female which ovulate spontaneously or are induced to super ovulate (Wolf et al., 2000). The current efficiency for producing transgenic animals particularly farm animals, is low and the cost is high. Success in the production of transgenic farm animals requires an adequate animal facility and dedicated teams of embryologists, veterinarians, animal scientists and molecular biologists. Ethiopia has over 57.83 million indigenous cattle, and about 13.5million are breeder cows and 28.89 million sheep out of which about 14 Million are kept for breeder and 29.7 million goats out of this 12.6 million are kept for breeder (CSA, 2015/16). Average milk production from local cows is also low, estimated at 1.37 liters/cow per day (CSA, 2014). This result in a total annual milk production of 3.81 billion liters and about $50 \%$ of this goes to calves Per capita milk consumption is low and stands at $19 \mathrm{~kg} /$ year FAO (2011). Therefore, Ethiopia needs to work hard on improving the work of productive and reproductive performance improvements of cattle through appropriate breeding and related activities (CSA, 2006). In spite, of the presence of large and diverse animal genetic resources, the productivity (meat and milk) of livestock remains low in many developing countries including Ethiopia for various reasons, such as inadequate nutrition, poor genetic potential, inadequate animal health services and other management related problems (Lobago, 2007). Cattle breeding are mostly uncontrolled in Ethiopia making genetic improvement difficult and an appropriate bull selection criteria have not yet been established applied and controlled which makes genetic improvement difficult (Webb,2003; Abraham ,2014). Given the considerable potential for smallholder income and employment generation from high-value dairy products, development of the dairy sector can contribute significantly to food security and nutrition of the country (Desalegn et al., 2009). On the other hand, artificial insemination (AI), the most commonly used and valuable biotechnology has been in operation in Ethiopia for over 30 years. Nevertheless, the efficiency and impact of the AI operation has not been well-documented (Engida, 2012). This paper is review status of reproductive technology to improved ruminant production in Ethiopia.

\section{LITERATURE REVIEW}

\section{Productive and Reproductive Performance of Dairy Cattle in Ethiopia}

Ethiopia have huge population of cattle thus, results obtained indicated that 98.95 percent of the total cattle in the country are local breeds. The remaining are hybrid and exotic breeds that accounted for about 0.94 percent and 0.11 percent, respectively (CSA, 2013). In spite of that the total number of both exotic and hybrid female cattle produced through the crossbreeding work for many decades in the country is quite insignificant indicating unsuccessful cross breeding work. This again suggests that Ethiopia needs to work hard on improving the work of 
productive and reproductive performance improvements of cattle through appropriate breeding and related activities (CSA, 2013). The average lactation yield of indigenous cattle breeds ranges between 400 to $680 \mathrm{~kg}$, have been reported whereas those of the crossbred cows range between 1200 to 2500 liters of milk over a lactation period of 279 days Belete et al. (2010). According to (Mekonen et al., 2012) Cattle have a significant contribution to the livelihoods of the farmers. They serve as a source of draught power for the agrarian population, by contributing towards the supply of milk, meat, manure besides being a source of ready cash, cattle also contribute significantly role to the socio-cultural values of the society. Appropriate breeding by using reproductive technology has great improvement on average lactation yield of dairy cattle Belete et al. (2010).

\section{Constraints of Production System in Ethiopia}

The constraints include subsistence-oriented production system, lack of awareness of improved livestock production system (by farmers, pastoralists/agro-pastoralists, professional and policy and decision-makers), feed resources, animal diseases and markets (Lobago, 2007; Azage et al., 2016). The burden of this huge livestock resource is also compromised by the poor reproductive performance, less use of reproductive technology with an annual calving rate of about $45 \%$. Out of this huge number of breeder cows, the annual number of calves born is only about 5.04 million. The remaining 6.16 million cows have to be fed and managed without producing either milk or calves. Again, about $15 \%$ of the calves die before attaining weaning age. This is a loss of about 756,000 calves every year. This huge reproductive wastage and pre-weaning calf losses could be averted through improved fertility management and reduced calf morality (Azage et al., 2016).

\section{Purposes of Using Reproductive Technology}

The main objectives of using reproductive biotechnologies in livestock are to increase production, reproductive efficiency and rates of genetic improvement or these reproductive technologies were initially to speed up the genetic improvements of farm animals by the increase of offspring of selected males and females and the reduction of the generation intervals.

\section{Types of Reproductive Technology Artificial insemination}

This technology has now become a practical technology in commercial dairy cattle programs in both developed and developmental countries. Artificial insemination (AI) is the process of collecting sperm cells from a genetically superior male animal and manually depositing them into the reproductive tract of a female. The first successful insemination was performed by Spallanzani, (1784) in a bitch. Pioneering efforts to AI were begun in Russia in 1899 by Ivanoff Ivanoff (1922) had studied AI in domestic farm animals, dogs, foxes, rabbits, and poultry. Later on, this technique was performed by various researchers worldwide in different species. Use of frozen semen (Polge et al., 1949) revolutionized the AI program through worldwide transport of semen. Initially, the AI was used to spread improved indigenous breeds which were followed by the introduction of crossbreeding, hence grade up the local low yielder breeds. The AI technology maximizes the use of outstanding males, dissemination of superior genetic material, improve the rate and efficiency of genetic selection on the male side, introduction of new genetic material by import of semen rather than live animals and thus, reducing the international transport costs, enabling the use of frozen semen even after the donor is dead and reduces the risk of spreading sexually transmitted diseases (Foote, 2002). Various aspects of AI technology have been globally standardized for each species. A large number of AIs are performed globally, more than 100 million cattle, 40 million pigs, 3.3 million sheep and 0.5 million goats are artificially inseminated every year (Boa-Amponsem and Minozzi, 2006). The conception rate from AI programs in developing countries is relatively low and therefore the desired goal from it has not been achieved, which may be due to the lack of proper management and poor technical skill. The AI will become more effective and economic only when farmers will have access to considerably better technical and organizational facilities.

Artificial insemination offers several potential advantages over natural service, of these, the reason most commonly advocated is as a means of genetic improvement and others include cost effectiveness, disease control, safety breeding, flexibility, and fertility management ( Ball and peter, 2004; Gebremedhin, 2005; Holm et al., 2008). Artificial insemination (AI) management programs are highly dependent upon accurate heat detection procedures to achieve successful results. Conducting two to three daily visual heat detection observations of the cattle herd during the AI breeding season could lead to economic benefits to beef and dairy producers. Efficient heat detection, however, is time-consuming, labor-intensive, and requires good management and recordkeeping. Undetected heats in an AI program play a significant role in lowering reproductive efficiency by increasing the number of "open days," which in turn results in longer calving intervals and ultimately reduces the net return to the producer (Dup onte, 2007). 


\section{The practice of artificial insemination in Ethiopia}

In Ethiopia, AI was first introduced in 1938 in Asmara, when Eretria was part of Ethiopia, however the process was interrupted due to the 2nd World War and restarted in 1952 (Yemane et al., 1993). It was again discontinuing due to unaffordable expenses of importing semen, liquid nitrogen and other related inputs. In 1967, an independent service was again restarted in the Arssi Region, Chilalo Awraja under the Swedish International Development Agency (SIDA). This is to manage the largest livestock population in Africa, but the productivity of animals is very low due to many reasons. This large potential for dairy production development due to the country's favorable climate which supports use of improved, high yielding animal breeds and offers a relatively disease-free environment for livestock development. Given the considerable potential for smallholder income and employment generation from high-value dairy products, development of the dairy sector can contribute significantly to food security and nutrition of the country. The Land O'Lakes report indicated that most of the milk (85\%) produced by dairy households is consumed by the household (Kefyalew et al., 2015). Therefore, Weak performance of the AI system has led to the country to having only about 350,000 improved dairy type animals Azage (2012).

According to Azage et al, (2010) AI service in Ethiopia is mainly provided by a government institution named National Artificial Insemination Centre (NAIC) which was established in Kaliti in 1981. In the country national artificial insemination service mainly focuses on cattle to boost milk production and uses exotic and local semen as appropriate. Exotic semen includes Friesian and Jersey, while the indigenous include Fogera, Horro, Boran and Begait(Azage, 2010). Thus, from (1997 - 2000 G.C) most of the inseminations were done in Addis Ababa (33.7\%) and Oromia (37.5\%) followed by Amhara (13.9\%) and SNNPR (9.4\%). Benefits from the use of AI are numerous, frozen semen can be transported globally and stored for a long period of time, the risk of disease infection and injury is minimized (DestaKelay, 2002 Melkamu, 2016). From a genetic improvement point of view AI is beneficial because it increases selection intensity of bulls and allows efficient bull usage (Cunningham, 2010). The use of AI in Ethiopia is growing but estrus detection is difficult owing to poorly expressed estrus of Zebu breeds (Mukassa-Mugerwa, et al., 1989; Tadesse, 2015). The efficiency of AI delivery system in the country, however, has remained at a very low level. This can be attributed to infrastructure, managerial, and financial constraints and also due to poor estrus detection, improper timing of insemination, lack of readily available inputs, besides overall logistics and management of the system at the official level, this is further quantified with poor health management of the cattle and embryonic death (Shiferaw, 2003; Hayleyesus, 2006), Likewise. The most important constraints associated with were loss of structural linkage between AI Center and service giving units, absence of collaboration and regular communication between National Artificial Insemination Center (NAIC) and stakeholders, lack of breeding policy and herd recording system, inadequate resource in terms of inputs and facilities, and absence of incentives and rewards to motivate AI technicians (Desalegn 2008).

Despite inappropriate selection and management of AI bulls along with poor motivations and skills of the inseminators (Dessalegn, 2008) further aggravate the problem associated with the efficiency of the system. Some farmers due to long distance of the AI centers from the beneficiaries, they faced problems of delivering their animals for the service and technicians also challenged with absence of transport facilities to offer the service on time of insemination (Tadesse et al., 2014). Currently artificial insemination (AI) technicians must travel door to door and are only able to inseminate an average of 3 cows per day. In many cases, they arrive too late in the cow's estrus cycle and insemination cannot take place on time (MAIFEC, 2014).

\section{Number of service per conception (NSPC)}

According to (Menale et al., 2011) NSPC is defined as the number of services/ inseminations required for a successful conception. It depends largely on the breeding system used and influenced by both genetic and nongenetic factors viz. season; that related to availability of feed, semen quality, lactation length, milk yield and parity (Gebrekidan et al., 2012). Fertility of the bulls is commonly measured by calculating the percentage of cows those are pregnant after a single service (Quintela et al., 2004: Debir et al., 2016). Numbers of service per conception is presented as follows.

Table 1: Number of service per conception (NSPC) of Bos indicus Zebu and cross breed cattle

\begin{tabular}{lll}
\hline Breed & NSPC/(mean value $)$ & Sources \\
\hline Local & 1.9 & Debir et al. $(2016)$ \\
Local & 2.2 & Kumar et al $1 .(2014)$ \\
Horro & 2.1 & Demissu et al. $(2013)$ \\
Fogera & 1.28 & Menal et al. $(2011)$ \\
Horro-Jersey & 1.8 & Demissu et al. $(2013)$ \\
Fresianx Zebu & 1.56 & Belay et al. $(2012)$ \\
Cross bred & 1.5 & Debir et al. $(2016)$ \\
Eastern low lowland Crossbred & 2.2 & Emebet and Zeleke $(2007)$ \\
Frisian x zebu & 1.3 & Nibret, $(2012)$ \\
\hline
\end{tabular}


Table 2: Regional AI service efficiency (2008/09)

\begin{tabular}{lcccc} 
Region & $\begin{array}{c}\text { Services } \\
\text { Conception, NSPC }\end{array}$ & $\begin{array}{r}\text { Variable } \\
\text { Non } \begin{array}{r}\text { Return } \\
\text { NRR (\%) }\end{array}\end{array}$ & $\begin{array}{c}\text { Rate, } \\
\text { Conception } \\
\text { CR (\%) }\end{array}$ & Rate, \\
\hline Tigray & 1.5 & 89.3 & 65.6 \\
Amhara & 2.5 & 77 & 39.4 \\
Oromia & 2.8 & NA & 34.5 \\
SNNP & 3.3 & 91.7 & 29.5 \\
Average & 2.52 & 86 & 42.25 \\
\hline
\end{tabular}

According to NAIC (2011), the average on-station NSPC was 1.93 with an average minimum of 1.75 at Holeta Research Centre and 2.23 at Asella farm over a period of four years (2002/3 to 2005/6) (Table3).

Table 3: Number of Services per Conception on three stations

\begin{tabular}{llllll}
\hline Station & NSPC & & & & Average \\
& $2002 / 3$ & $2003 / 4$ & $2004 / 5$ & $2005 / 6$ & \\
\hline Holetta Agricultural Research Center & NA & 1.5 & 1.85 & 1.9 & 1.75 \\
Asella Farm & 2 & 2.2 & 2.5 & NA & 2.23 \\
Holetta Cattle Genetic Improvement Farm & 1.7 & 1.8 & 2.18 & 1.83 & 1.88 \\
Average & 1.85 & 1.83 & 2.18 & 1.86 & 1.93 \\
\hline
\end{tabular}

Source: NAIC (2011)

NSPC: Total number of service (inseminations) per conception (cows conceived); NRR: Proportion of cows not returned for $2^{\text {nd }}$ insemination from total number of $1^{\text {st }}{ }_{\text {inseminated cows; }}$ CR: Proportion of number of pregnant cows from total number of inseminations (conception rate), NA: Not Available

Figure 1: Number of inseminations, pregnancies and calves born (cattle) for ten references years $(2001-2010)$

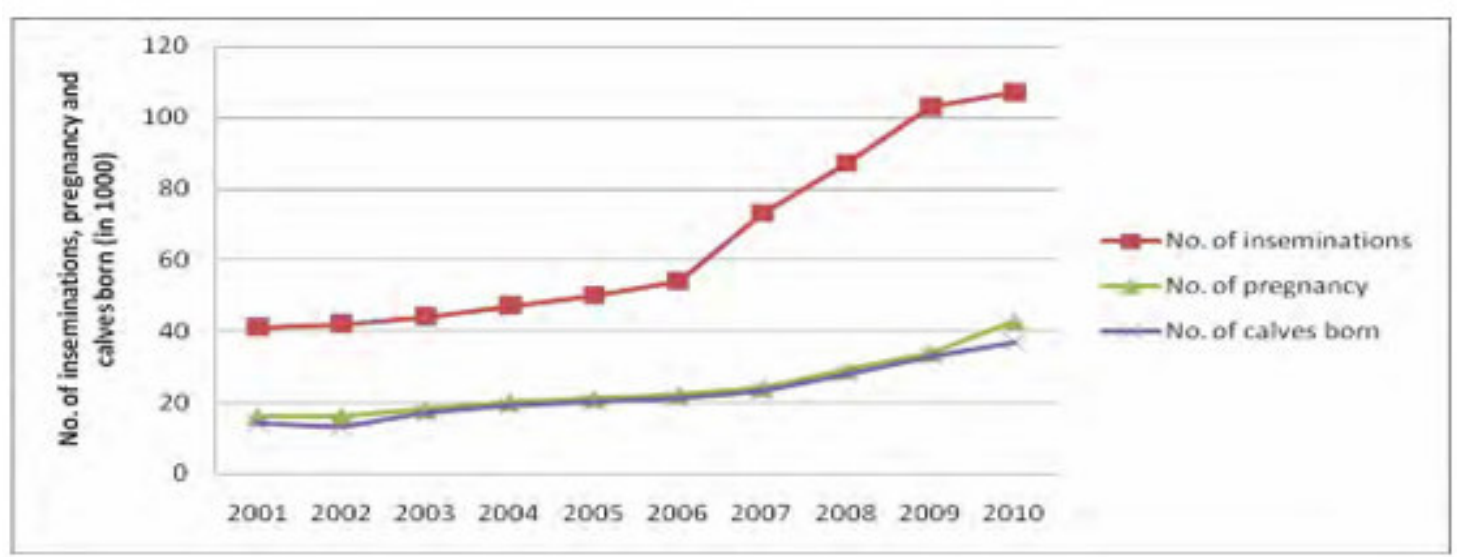

Source: CSA (2001-2010)

\section{Enrollment of semen producing bulls}

According to (Zewde, 2007), the selection criteria of bulls for AI service must include record-based pedigree information, individual performance as regularly recorded starting from the time of birth, which should include birth weight, subsequent weight increments. Later on progeny testing and general health status should also be parts of the selection criteria. Thus, AI service is weak and even declining due to inconsistent service in the smallholder livestock production systems of the Ethiopian highlands. The problem is more aggravated by wrong selection and management of AI bulls along with poor motivations and skills of inseminators (GebreMedhin, 2005; Alazar et al., 2015). Registration as semen producing bulls is not only enough, proper managements and Bull health control is essential to sustain semen production. Therefore, Disease prevention in bulls has been considered as essential as in breeding females (Hansen, 2006). Unless it is made possible to make full control of the health of bulls selected for semen production, the disadvantages of artificial insemination in disseminating diseases will be much higher (Zewde, 2007). The frequency of tests made and the diseases tested at NAIC are not sufficient (Agegnehu, 2007). According to the international animal health code (2001) of the Office International des Epizooties (OIE), donor and teaser animals should be tested for the following specific diseases: Bovine Brucellosis, Bovine Tuberculosis, Bovine Viral Diarrhea, Infectious Bovine Rhinotracheitis, Campylobacter fetus/subspecies veneralis, Trichomonas fetus. Nevertheless, semen-producing bulls at NAIC in Ethiopia are tested only for brucellosis and tuberculosis and yet not on regular basis due to many associated constraints (Agegnehu, 2007). 


\section{Artificial insemination technician efficiency}

According to Makh (2008) the site of semen deposition has been an important factor in the success of AI in cattle accurate placement is important for achieving good conception rates. Faulty insemination technique is major factor causing low conception rate in many herds accurate insemination to detail, a clear understanding of reproductive anatomy and the ability to identify the target area and properly position the insemination road.

\section{Heat detection and timing of insemination}

Knowledge of estrus behavior and the estrus to ovulation interval is essential for estimating the best time to artificially inseminated cattle (Reolofs et al., 2010). According to kuster (2004) and Tegenu, (2016), Heat detection is basic to reproductive success in artificially bred herds. A Frequent question concerning AI is what time during estrus should cow in bred for greatest chance of conception? Since estrus may last from 10-25 hours there is considerable latitude in possible time of insemination. Maximal conception is obtained when cows are inseminated between mid-estrus and end of standing estrus, with good results up to 6 hours after estrus. A successful heat detection program and subsequent proper timing of insemination will pay dividends in increasing reproductive efficiency.

Table 4: showing proper timing of insemination

\begin{tabular}{|l|l|l|}
\hline Cow show estrus & Should be inseminated & To be late for good result \\
\hline In morning & Same day & Next day \\
\hline In after noon & Moring of next day or & After 3 pm next day \\
\hline & Early after noon & \\
\hline
\end{tabular}

Source (webb, 2003; Tegenu 2016).

\section{Distribution of semen in Ethiopia}

NAIC distributes semen to nine sub-centres: two in Oromia (Nekemt and Asella), two in SNNP (Wolaita and Wolkite), two in Amhara (Bahir Dar and Dessie), two in Tigray (both in Mekelle) and one in Harari (Harar). These places are selected for their strategic locations and all the semen is sent on request to the Regional Agricultural Bureaus, which are responsible for distributing liquid nitrogen and semen to sub-centers in their respective regions. Zelalem et al, (2011), Ethiopia, for various reasons, such as inadequate nutrition, poor genetic potential, inadequate animal health services and other management related problems (Fikre, 2007). Livestock productivity in Ethiopia is said to be poor due to a number of reasons among which is the low genetic capacity of the indigenous cattle. In the country the poor genetic potential for productive traits, substandard feeding, poor health care and management practices are the main contributors to low productivity (Belay et al., 2012). In order to improve the low productivity of local cattle, selection of the most promising breeds and cross breeding of these indigenous breed with high producing exotic cattle has been considered as a practical solution. Crossbreeding work in Ethiopia was initiated in the early 1950s, following this initiation a number of governmental (example, Ethiopian Agricultural Research Organization, Ministry of livestock and fishery, National Artificial Insemination Center, Higher Learning Institutes) and non-governmental organizations (International Livestock Research Institute and Swedish International Development Agency) have worked in the development of the dairy sector. These crossbreeding activities, unfortunately, were not based on clearly defined breeding policy with regard to the level of exotic inheritance and the breed types to be used. The unplanned crossbreeding had also threatened the genetic resources base of the country (Azage, 2011). Similarly, the effect of crossbreeding has also been disastrous, especially in the smallholder sector where less attention is paid to matching the genotype to the environment (Kahi 2002; Chencha, 2012).

\section{The position of pregnancy rate/conception rate in Ethiopia}

Pregnancy rate/conception rate refers to the percentage of cows /heifers diagnosed pregnant out of total number of cows/ heifers inseminated (Miah et al., 2004). According to (Hamid 2012; Adebebay et al., 2013; Tewodros et al.,2015) an averages of conception rate have been reported $48.1 \%, 13.7 \%$ and $31.29 \%$, respectively in different milk shade area of the country. The average national conception rate $27 \%$ have been reported Desalgn (2008). Conception/ reproductive performance is associated to either to the management factors (such as husbandry, feeding, estrus detection and time of artificial insemination, semen handling) or cow factors such as age, body condition score, post-parturient problem, disease events, milk yield and genetics.

\section{Estrus synchronization}

Reproductive failure in inseminated cattle results from poor fertilization and embryo survival. Several factors affect fertilization rates, but the greatest impact was observed for high producing cows under heat stress, when fertilization was only $55 \%$. Once fertilization has occurred, the fate of a successful pregnancy is then determined 
by the survival of the embryo and fetus (Santos et al., 2004). Perfect detection of estrus is crucial for good husbandry practice of cow. Estrus synchronization is the alternative strategy to bypass the critical problem of estrus detection (Paul et al., 2015). Synchronization of estrus implies the manipulation of the estrous cycle or induction of estrus to bring a large percentage of a group of females into estrus at a predetermined time (Odde, 1990). Estrus synchronization programs improve reproduction efficiency by reducing the length of breeding and calving seasons and increasing calf weaning weights (Gupta et al., 2008). The reproductive performance of a dairy herd has a significant effect on the profitability of that herd. Common measures of reproductive performance are days to first service, days to conception, calving interval, services per conception, conception rate, estrus detection rate, and pregnancy rate. Pregnancy rate is an overall measure of reproductive performance (AlbertdeVries et al., 2012).

Besides Synchronization is regulating follicular development; provide multiple stimuli designed to induce anestrous females to cycle, and treatments that synchronize ovulation for the purposes of timed AI. Besides, the wide application and success of AI and estrus synchronization throughout the developed world and the success rate in African and other developing countries is still low owing to a number of technical, system related, financial and managerial problems (Tropentag, 2012). Synchronization of the estrous cycle has the potential to shorten the calving season, increase calf uniformity, and enhance the possibilities for utilizing AI (Lamb, 2010). The aim Estrus Synchronization is to bring a group of female for parturition: decrease labor, and financial resources, decrease calving period reduce calving season more uniform weaning weights. Reduce or eliminate estrus detection needed for artificial insemination (Azage, 2012). Truthful economic benefits of improved reproductive performance are not simple to estimate. When reproductive performance improves, all changes in cash flows that result from the improvement must be accounted for. So for a good analysis, we need at least realistic estimates of lactation curves, feed intake, the risk of involuntary culling, and prices such as for milk, feed, labor, semen, fertility drugs, calves, replacement heifers and cull cows (Albert de Vries et al., 2012). Estrus synchronization can avoid or reduce the need for estrus detection, and increases the fertility and productivity of cattle (Larson et al, 2006). Furthermore, estrus synchronization facilitates planning of AI, shortens first day service in postpartum cows, reduces the calving interval and helps to maintain uniform calf crops and replacement heifers (lamb, 2010; Larson et al., 2006). However, the benefits from this method can only be obtained from a reproductively healthy cow. Non-cycling cows or anestrous cows, a condition where the cow does not cycle due to insufficient natural hormonal stimuli cannot be induced to restore her reproductive cycle using this technique (Pennington, 2013). The technique of estrus synchronization can significantly assist the already existing reproductive management tools. The technology needs to be disseminating to the cattle breeder, veterinarians and industry personnel to ensure they are adopted at the producer level and to provide the necessary technical support to achieve optimum results (Lamb, 2010).

\section{Estrous synchronization protocols}

Various estrous synchronization protocols are available in the world. Some commonly used estrous/ovulation synchronization protocols in dairy cattle includes use of prostaglandin (one shot method and two-shot method) and progestin (Ovsynch and Cosynch) (Rick, 2013). Current world-wide research is focused on the development of methods that effectively synchronize estrus by decreasing the period of time over which estrus is detected, hence facilitating the use of fixed time AI (Patterson et al., 2011). Progesterone based estrus synchronization protocols are more advantageous than others.

One shot method: A single injection of PGF2 $\alpha$ is given to cyclic females, and then these females are bred as express estrus or the method used only for cows having a functional CL will be injected. These cows should show sign of oestrus within 2-3 days Lucia (2013). The disadvantage of this program is that $20-25 \%$ of the females will not respond to the injection, likewise, the method has the disadvantage that animals have to be palpate or scan prior to be injected Lucia (2013) but the advantages are the lower cost of one injection and that females are only handled once other than for breeding (Islam, 2011).

Two shot method: The most common method of synchronization with PGF $2 \alpha$ is to inject all animals and breed those that come into heat over the next 5 to 7 days. The two injections of prostaglandin spaced 14 days apart (Islam, 2011). Detection of estrus is not required before or between injections. All cycling cows should respond to the second injection regardless of what stages of the estrous cycle were in when the first injection was administered. Remember the non-cycling cows will not generally respond to prostaglandin products. The advantage of this option is that more cows should come into estrus at any given time than with the one shot options. The disadvantage is that it involves the cost and labor of administering two injections of prostaglandin to all cows (Michael and Thomas, 2005; Păcală, et al., 2009).

Prostaglandin: Prostaglandin is the first method of heat synchronization that depends on the presence of a functional CL particularly in the diestrus stage of the estrous cycle (day 7 to 17 of the cycle) (Cordova-Izquierdo et al., 2009). Its effectiveness usually affected by heat stress, asynchronous ovarian events exhibiting incomplete or delayed luteolysis, and weak or delayed estrous (Mgongo et al., 2008; Lamb, 2010;Adebabay, 2013) similarly, Prostaglandin is used to synchronize estrus in dairy cattle operations to improve the efficiency of AI byinducing 
the regression of the corpus luteum and subsequently lead to the expression of estrus and ovulation with 2 to 5 days after their administration (Holm et al., 2008; Murugavel et al., 2010). Pregnancy rate from 61.4 to $65 \%$ in cycling and up to $47 \%$ in anestrus cows have been reported after a single injection of PGF2 $\alpha$ (Perry, 2010). According to (Baruselli et al., 2006) suggested that treatments using progesterone releasing devices and GnRH/ improve reproductive performance in Bosindicus cows due to their beneficial effect on Luteinized hormone pulse frequency, follicular growth and ovulation. In Ethiopia in different milk shade reported that the rate of estrus response in a single injection of prostaglandin protocol at the milk shade and farmer level was $97.7 \%$ and $91.3 \%$, respectively (Debir et al., 2011; Girmay et al., 2015) and likewise Adebebay et al. (2013) the average response rate of the cows to prostaglandin (PGF2 $\alpha$ ) injection or its analogue was $89.3 \%$. (Gupta et al., 2008). The advantage of Prostaglandin or its analogue (PGF2 $\alpha$ ) in a synchronization protocol shortens the estrous cycle when used alone and estrus is observed within 2 to 7 days' post injecting the hormone.

\section{Multiple Ovulation and embryo transfer (MOET)}

Multiple ovulation and embryo transfer (MOET) is often referred as the assisted reproductive technology that is "to the female, while AI is to the male", i.e. a method of producing more offspring from a genetically valuable female than would be possible by natural breeding. Meanwhile, MOET has not yet become a widespread tool for genetic improvement for a variety of reasons including its costs, technical demands, and variable and unpredictable efficiency (Cognié et al., 2003). An early review by Callesen et al. (1996) showed the significance of MOET in dairy cattle. Meanwhile, the use of MOET procedures remains affected by a high variability in the ovulatory response to hormonal treatment and by a low and variable number of transferable embryos and offspring obtained. This variability has been classically identified with both extrinsic (source, purity of gonadotrophins and protocol of administration) and intrinsic factors (breed, age, nutrition and reproductive status) (González-Bulnes et al., 2004). In a more recent review, Menchaca et al. (2010) summarized that the application of recently acquired knowledge has resulted in relevant improvements in MOET programs in small ruminants. Embryo transfer technology is an important tool to improve livestock at faster rate as well as gives an opportunity to utilize the genetic contribution of both male and female at the same time. Nicholas and Smith (1983) reviewed that with the help of ET (embryo transfer) or MOET (multiple ovulation embryo transfer) techniques a faster improvement of livestock, rapid expansion of elite animals, genetic gain, accelerated herd development and conservation of rare genetic stocks could be achieved.

Embryo transfer and other reproductive technology facilitate genetic improvement and have been successively used for rapidly multiplying the population of elite breeds of cattle (Thibier, 1996), buffalo (Madan et al., 1993), sheep (Holm et al., 1996), goat (Pawshe et al., 1994 and Baldassarre and Karatzas, 2004), horse (Squires et al., 1999) and pig (Hazeleger and Kemp, 1999). In 2002, approximately 539,680 ETs were performed worldwide, mainly in dairy cattle, with $62 \%$ being transferred in North America and Europe, $16 \%$ in South America and 11\% in Asia (Madan, 2005). Moreover, the latest report of the International Embryo Transfer Society Data Retrieval Committee estimated the number of ET transferred to be 800,000 embryos in cattle (Thibier, 2009), 25,000 in sheep, 7000 in goat, 30,000 in pig and 12,000 in horses (Thibier, 1996) were transferred worldwide (two thirds as in vivo derived embryos and one third as in vitro produced) with 55-70\% conception rate (Thibier, 2009).

After AI and estrus synchronization, embryo transfer (ET) is the third-most commonly used reproductive technology (Cowan, 2010). Embryo transfer from one mother to a surrogate mother makes it possible to produce several livestock progenies from a superior female. Selected females are induced to super-ovulate hormonally and inseminated at an appropriate time relative to ovulation depending on the species and breed. The technology is widely used globally in the cattle industry, with more than $1 / 2$ million embryos transferred annually. Super ovulatory treatment of donor cows enables production of a higher number of transferable quality embryos and higher probability of producing multiple offspring. Variability in the response to super ovulatory treatments seems to be affected by breed, and the dose of exogenous FSH required for super ovulation of Bos indicus cattle is typically $30 \%$ less than that for Bos taurus cattle. (Tamrat et al, 2016). However, embryo transfer is still not widely used despite its potential benefits in developing countries this is mainly due to absence of the necessary facilities and infrastructure. An evaluation of country reports FAO (2007). Shows that only five of the African countries providing information (Cote d'Ivoire, Kenya, Madagascar, Zambia and Zimbabwe) use ET technology, all on a very limited scale. The use of ET also been independently reported in South Africa. The first successful embryo transfers in Ethiopia, resulted in the birth of a Holstein-jersey calf at the Adami Tulu Animal Research Center in the beginning of May, 2010 and five more calves had born. In April 2010, eighty frozen embryos that were imported the previous August were implanted in the native cows Lonny (2010). And also Super ovulation of Boran Cattle in Ethiopia has been reported (Degefa et al., 2016).

\section{The Use of embryo transferring technology}

Embryo transfer increases reproductive rate of selected females, reduces disease transfer, and facilitates the development of rare and economically important genetic stocks as well as the production of several closely related 
and genetically similar individuals that are important in livestock breeding research (Thibier, 2005). Likewise, Embryo transfer is used to increase the number of offspring that can be obtained from valuable female animals and is mostly used in cattle. Embryos for transfer can be produced in vivo (inside the body) or in vitro (in the laboratory). In vivo embryo production using a technique known as MOET (multiple ovulation and embryo transfer) is used for the production of $80 \%$ of embryos for commercial purposes worldwide (Schmidt, 2007). Thus, embryo transfer has the potential to bring about genetic improvement twice as fast as AI alone. Moreover, the use of MOET technique could lead to increased selection intensity and reduced generation intervals, resulting in improving genetic gains. However, embryo transfer is still not widely used despite its potential benefits. In developing countries this is mainly due to absence of the necessary facilities and infrastructure an evaluation of country reports (FOA, 2007). The procedures for removing the eggs or embryos from the donor cow and transferring the embryos to the recipient cows are invasive, generally requiring epidural anesthesia. Cows may be subjected to repeated cycles of MOET or ovum-pick-up, (OPU). There is a risk of pain and infection at the epidural injection site, which may extend to the bone and other tissues (McEvoy et al., 2006).

\section{Cloning}

Cloning is a powerful technique and potentially it could be used for multiplication of elite animals and minimize the genetic variation in experimental animals. It can be used for the conservation as well as tool for the production of stem cells for therapeutic purposes, as therapeutic cloning. Cloning using somatic cells offers opportunities to select and multiply animals of specific merits (Das et al., 2003). Numerous types of somatic cells are used as donors in somatic cloning; foetal fibroblasts, adult fibroblasts, granulosa cells, hepatocytes, lymphocytes etc. (Campbell et al., 2007). The birth of Dolly in 1996, the first animal cloned from an adult cell, was not universally celebrated. Critics of biotechnology worried that genetically modified livestock would fill the supermarket with identical copies of someone's idea of unnatural perfection Alison (2008). Up to 2004, about 1500 calves had been produced through somatic cell nuclear transfer (SCNT), mainly in Europe, North America, Japan and New Zealand, but also in South America and Asia Heyman, 2005. China produced the first cloned buffalo in 2004 and India followed suit in February 2009. At present the production of cloned animals is at the experimental stage in most developing countries.

Figure1: Cloning by SCNT

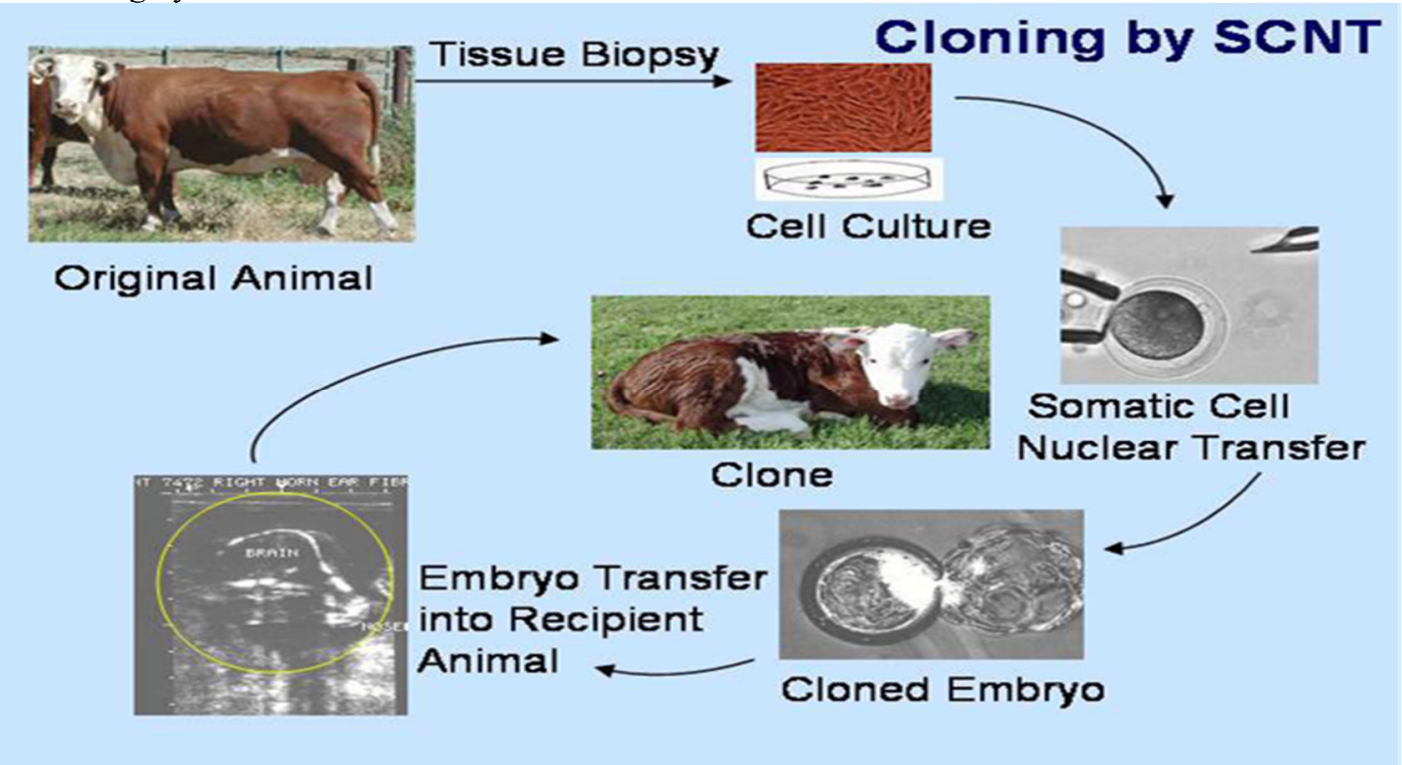

Embryo splitting involves bisecting the multi-cellular embryo at an early stage of development to generate clones or "twins." A 32-cell embryo, for example, might be bisected into two 16-cell twins. This type of cloning occurs naturally (human identical twins result from this process, but fraternal twins do not), but it can also be performed in a laboratory where it has been successfully used to produce clones from a number of different animal species Alison (2008). 
Figure 1: Cloning by embryo splitting

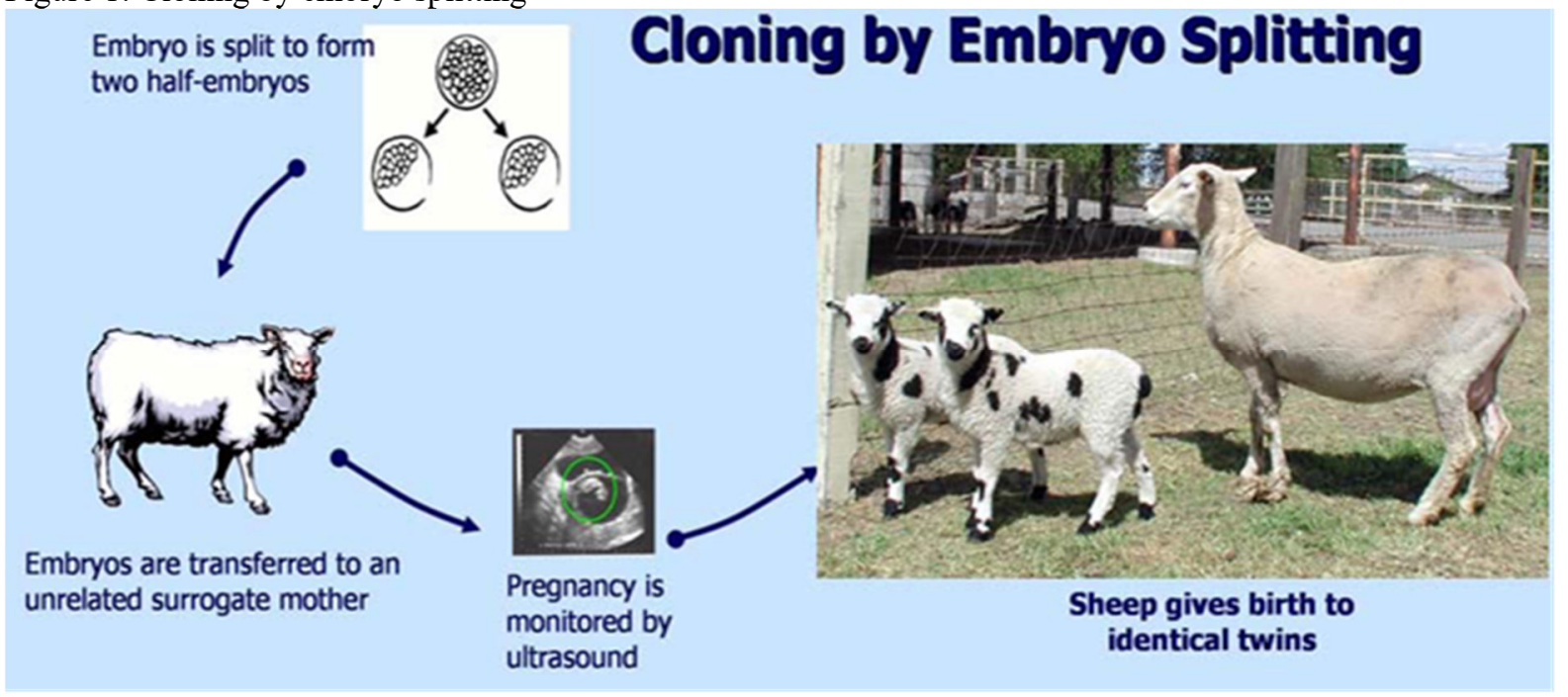

Table (5). The successful nuclear transfer in some farm animals

\begin{tabular}{|c|c|c|c|c|}
\hline Species & Name & Method & Date issued & Organization \\
\hline Sheep & Dolly & Nucleartansfer(Fusion)* & Feb 1997 (Nature) & Roslin Institute, UK \\
\hline Cattle & Dolly & Nucleartransfer (Fusion) & Dec 1998 Science) & Kinki University at Japan \\
\hline Goat & Dolly & Nucleartransfer (Fusion) & May1999(Nature biotech) & Tufts University \\
\hline pig & Xena & $\begin{array}{l}\text { Nucleartransfer } \\
\text { Microinjection)** }\end{array}$ & Aug 0 (Science & Animal Industry at Japan \\
\hline Camel & Injaz & $\begin{array}{l}\text { Nuclear } \\
\text { (Microinjection }\end{array}$ & $\begin{array}{l}2020010 \quad \text { (Biology } \\
\text { Reproduction) }\end{array}$ & $\begin{array}{l}\text { Camel Reproduction Centre } \\
\text { at Dubai, UAE }\end{array}$ \\
\hline
\end{tabular}

*The nucleus from an udder cell was fused with an enucleated oocyte then implanted into a surrogate mother and developed. **The nucleus from a cumulus cell was injected into an enucleated oocyte then implanted into a surrogate mother and developed.

\section{Semen and embryo sexing}

Though these biotechnologies do not dramatically increase the rate of genetic gain, they can increase production efficiency. According to FAO, 2007 at a research level, they are being developed and refined in a number of research institutions in developing countries. However, with few exceptions, they are not widely used by breeders or farmers in developing countries. Sexed sperm is commercially available in several developing countries, including Ehiopia Argentina, Brazil and China (Garner, 2006; Rath, 2008).

\section{In- vitro fertilization}

According to Cowan (2010) in case other artificial reproductive techniques fail due to difficulties such as blocked reproductive systems, non-responsive ovaries in the females, marginal semen quality and quantity in the male, and presence of disease, in vitro fertilization (IVF) is used. The fertilization of the sperm and the egg is conducted in vitro (outside the animal's body) at specific environmental and biochemical conditions. Within vitro fertilization (IVF), a technician removes unfertilized eggs (oocytes) from the donor cow's ovaries, usually recovering 6-8 useable oocytes. The oocytes mature in an incubator and are fertilized with sperm. The resulting zygotes incubate and develop in the laboratory before being placed into the recipient cow. Thus, the IVF procedure for bovine embryos consists of three steps. first, in vitro maturation (IVM) of primary, germinal vesicle-stage oocytes collected directly from the ovaries of donor females, second, IVF by combining in vitro matured oocytes with in vitro capacitated sperm cells and third, in vitro culture (IVC) of presumptive zygotes to stages of development that allow them to be transferred to female recipients Rajesh (2015). For IVF in cattle, the percentage of live offspring per transferred embryo is $45-60 \%$ (Chavatte-Palmer et al., 2012). These embryo transfers provide a complete set of new genes and greater genetic gains over that obtained with artificial insemination, where only the paternal half of the genome can be introduced. Supplying embryos from slaughter house oocytes for twinning programmes to increase calves without increasing the number of cows.

\section{Nanotechnology}

Nanotechnology is recent advancement in cellular and molecular biotechnology. It has an enormous potential to 
revolutionize agriculture and livestock sector. This technology allows researchers to handle biological materials and media in minute quantities usually nanoliters or picoliters. In addition to its applications in cellular biology, biotechnology, theraputic medicine and genetics, it might be useful technique in farm animal breeding and reproduction. Micro fluidic and nano fluidic (Schuster et al., 2003; Eijkel and Berg, 2005) are recent tools to simplify traditional procedures of in vitro fertilization (IVF) and in vitro embryo production (Suh et al., 2006). More recent reports have demonstrated the utility of microfluidics in isolation of motile sperm without centrifugation (Schuster et al., 2003). Oocyte manipulation under in vitro condition can also become feasible with advent of this technique (Beebe et al., 2002). Glasgow et al., (2001) first established that manipulation and movement of an embryo in a microfluidic environment. It can also be used in sorting of sperm and eggs, these systems control the flow of liquids or gases through a series of micro and nanoscale channels and valves, which is assisted with computer circuit for data analysis. Nanotechnology has its application in genome mapping and sequencing furnishes a hope to identify gene sequences that relate to commercially valuable traits such as disease resistance and leanness of meat. By including probes for these traits on biochips, breeders will be able to speedily identify elite breeders and screen out genetic diseases. In farm animal breeding heat detection can be done by implanting a nanotube (O'Connell et al., 2002) under the skin to detect the changes in the level of estradiol in the blood. The signal from this sensor will be incorporated as a part of a central monitoring and control system to actuate breeding.

\section{Laser technology}

Laser effects on sperm motility parameters, improvement of oocyte maturation and characterization of semen in livestock have been reviewed (AbdelSalam and Harith, 2014). Several application of laser had been reviewed as assisted techniques of reproductive technology to benefit the energy from different types of laser to excite either sperm of oocyte to improve their competence toward fertilization. Also, they mentioned the promising types of laser and wave length in the applications of improving semen parameters either pre- or post- thawing, oocyte maturation for IVF, and avoid the bacterial contamination shorter wavelengths, e.g. $\lambda=532 \mathrm{~nm}$ and $\lambda=405 \mathrm{~nm}$ is promising and more reasonable than longer laser wavelength for bio simulative purposes because they will be better absorbed by the cellular chromophores. The limited publication in this new field reduces the awareness and the speared of such technique in routine field work.

SUMMARY: Review was done on potential of reproductive technology to improved ruminant production in Ethiopia. Reproductive technology encompasses all current and anticipated uses of technology in animal reproduction, including assisted reproductive technology, contraception and others. The aims of these reproductive technologies were initially to speed up the genetic improvements of farm animals by the increase of offspring of selected males and females and the reduction of the generation intervals. research into physiology and embryology has provided a basis for the development of technologies that increase productivity of farm animals through enhanced control of reproductive function. animal reproductive technology represents an expanding collection of rapidly developing disciplines in science and information technologies. the livestock provides many opportunities to utilize these disciplines and evolving competencies. artificial insemination, synchronization, embryo transfer, in vitro fertilization, cloning, transgenic and genomics all are components of the tool box for present and future applications. individually, these are powerful tools capable of providing significant improvements in productivity. combinations of these technologies coupled with information systems and data analysis will provide even more significant changes in the next decade. various techniques have been developed and refined to obtain a large number of offspring from genetically superior animals or obtain offspring from infertile (or sub fertile) animals. to take full advantage of the benefits of assisted reproductive technologies, one must understand the basic physiology of the female and male reproductive systems. from those types of reproductive technology, artificial insemination, estrous synchronization and fewer amounts of multiple ovulation and embryos transfer are now implementing in Ethiopia.

CONCLUSIONS: Assisted Reproduction Technologies (ART) in farm animals is recently receiving renewed attention. Reproductive Technology can be used to meet the increasing country desire for animals' products and to overcome reproduction failure in high producing animals. On the other hand, artificial insemination is the most commonly used and valuable reproductive technology and the practice in cattle goes back to 1938 in Ethiopia, Despite, the efficiency of AI delivery system in the country, has remained at a very low level. Estrus Synchronization the second most important technology in the country to improve productivity of the animal it used to bring a group of female for parturition: decrease labor, and financial resources, decrease calving period reduce calving season more uniform weaning weights. Reduce or eliminate estrus detection needed for artificial insemination. Various estrous synchronization protocols are available in the world. Some commonly used estrous/ovulation synchronization protocols in dairy cattle includes use of prostaglandin (one shot method and two-shot method) and progestin. The most important reproductive technology after AI and estrus synchronization is embryo transfer (ET) is third used reproductive technology in Ethiopia to improve ruminant productivity. 
Embryo transfer from one mother to a surrogate mother makes it possible to produce several livestock progenies from a superior female. The following recent reproductive technologies are not practice in Ethiopia namely, Cloning, semen embryo sexing, and in vitro fertilizations, laser technology, in vitro embryo production (IVP), Intra-cytoplasmic sperm injection (ICSI) and nanotechnology.

\section{Recommendation:}

* Research institute should implement reproductive technology in station and transfer to developmental agency workers and farmers.

* Practical oriented and sustainable training should be given for reproductive technology technicians to prevent conception rate failure.

* AI, synchronization, Embryo transferring and other reproductive technology should strictly follow the standard guidelines and procedures set for the purpose and also the national livestock development policies of the country

\section{REFERENCE}

Abraham, H. and Pal. S., K. 2014. Animal Biotechnology Options in Improving Livestock Production in the Horn of Africa Department of Animal and Range Sciences, BuleHora University, Ethiopia.InternationalJournalofInterdisciplinaryandMultidisciplinaryStudies

Adebebay Kebede, GetinetZeleke, YeshwasFerede, Temesegen Abate and AzageTegegne 2013. Prostaglandin (PGF2 $\alpha$ ) based oestrous synchronization in postpartum local cows and heifers' in Bahir Dar milkshed, Int. J. Pharm. Med. andBio. Sc. 2(4)

Agegnehu, B. 2007.Performance evaluation of semen production and distribution team for 2006/07 fiscal year NAIC Addis Ababa.

AL- Makh, zoomi, Lundeheim, N, Hoord,M and kodriguez Martinez, H. 2008. Sperm morphology and fertility of progeny -tested AI dairy bulls in Sweden theriogenology 70; 682-691.andro 125(2); 255-264.

AlazarWoretaw, BemrewAdmassu, Anmaw Shite and Saddam Mohammed, 2015. Assessment of Problems Associated with Artificial Insemination Services in Dairy Cattle in Debretabour Town, Ethiopia,

Albert de Vries, Jessika van Leeuwen, William W., and Thatcher, 2012. Economics of improved reproductive performance in dairy cattle, University of Florida, Institute of Food and Agricultural Sciences, Cooperative Extension Service, Gainesville, 32611.

Alison Van Eenennaam, 2008.Animal cloning Cooperative Extension Specialist University of California Department of Animal Science.

AzageTegegne, 2010. Livestock input supply and service provision in Ethiopia: Challenges and opportunities for market-oriented development paper no.20, 11.

AzageTegegne, Awet Estifanos, AsratTera and Dirk Hoekstra, 2012. Technological options and approaches to improve smallholder access to desirable animal genetic material for dairy development: IPMS Experience with hormonal oestrus synchronization and mass insemination in Ethiopia.

AzageTegegne, Belete Anteneh, FekaduBeyene and BerhanuGebremedhin. 2010. Characterization of cattle milk and meat production and marketing system and opportunities for market-orientation in Fogera district, Amhara Region, Ethiopia. IPMS Working Paper No. 19. Nairobi: ILRI.

AzageTegegne, Dirk Hoekstra, BerhanuGebremedhin and Solomon Gizaw. 2016. History and experiences of hormonal oestrus synchronization and mass insemination of cattle for improved genetics in Ethiopia: From science to developmental impact International Livestock Research Institute (ILRI) lives working paper no 16, 1.

Ball P. J., H. and Peters A., R. 2004. Reproduction in Cattle Third edition Fibiol Pp.1-13 Baruselli, P.S., S á Filho, M.F., Martins, C.M., Nasser, L.F., Nogueira, M.F., Barros C.M., \&Bó, G.A. (2006). Superovulation \& embryo transfer in BosIndicus cattle. Theriogenology, 65, 77-88.

Beebe, D., Wheeler, M., Zeringue, H., Walters, E. and Raty, S. (2002). Microfluidic technology for assisted reproduction. Theriogenology, 57:125-135.

Bekana, M., Gizachew A. and Regassa, F. 2005. Reproductive Performance of Fogera heifers treated with prostaglandin F2 $\alpha$ for synchronization of oestrus Tropical Animal health and Productio

Belay, D.Yisehak, K. and Janssens G. P. J. 2012. Productive and reproductive performance of Zebu X HolsteinFriesian crossbred dairy cows in Jimma town, Oromia, Ethiopia. Global Vet. 8 (1):

Belete, A., Azage T, Fekadu B. and Berhanu, G. 2010. Cattle and Meat Production and marketing systems and opportunities for market orientation in FogeraWoreda, Amhara region, Ethiopia. IPM S of Ethiopian Farmers Project Working Paper 19. ILRI, Nairobi, Kenya, pp 65. Cattle, Siltie Zone.Degree of Master of Science in Veterinary Obstetrics and Gynaecology.

Central Statistical Agency, CSA, 2014. Agricultural sample survey 2013/14 Report on livestock and livestock 
characteristics Addis Ababa, Ethiopia 2(573).

Central Statistical Agency, CSA, 2016.Agricultural sample survey 2015/16 Report on livestock and livestock characteristics Addis Ababa, Ethiopia 2(583).

Central Statistics Agency, CSA, 2006. Federal Democratic Republic of Ethiopia Agricultural Sample Survey 2006, volume II, Report on livestock and livestock.

Chavatte-Palmer P, Camous S, Jammes H, Le Cleac'h N, Guillomot, M. and Lee RSF, 2012.Review: Placental perturbations induce the developmental abnormalities often observed in bovine somatic cell nuclear transfer Placenta, 33 Suppl, S99-S104.

Chebel, R.C., 2010. Mastitis and BCS Loss Affects Fertility DVM Thesis Department of Veterinary Medicine University of Minnesota.

Chencha Chebo and KefyalewAlemayehu, 2012. Trends of cattle genetic improvement programs in Ethiopia: Challenges and opportunities Wollo university, Department of Animal Sciences,

Cordova-Izquierdo A C A, Cordova-Jimenez M S, Cordova-Jimenez C G and Ruiz L J A ,2009 "Oestrus synchronization and percentage of pregnancy in dairy calves using prostaglandins by two via of administration", Australian journal of basic applied sciences, Vol. 3, No. 3, pp. 2834- 2837.

Cowan, T.2010. Biotechnology in Animal Agriculture: Status and Current Issues Analyst in Natural Resources and Rural Development [www.crs.gov] RL32809.

CSA, 2010.Agricultural Sample Survey, Livestock, Poultry and Beehives population (private peasant holdings). Federal Democratic Republic of Ethiopia Central Statistical Authority, Addis Ababa, Ethiopia.

Cunningham E. P., 2010 A time of change Journal of Animal Breeding and Genetics 127 (6), pp 419- 420.Dairy Cows Artificially Inseminated During Natural Heat and by Synchronization in Fogera

Debir Legesse Belay, AsratTera and AzageTegeng, 2016. Evaluating the Efficiency of Artificial Insemination Following Estrus Synchronization of Dairy Cattle in Southern Region, Ethiopia: The Case of Dale District Hawassa Agricultural Research Center Hawassa, Ethiopia, Journal of Natural Sciences Research Vol.6, No.5,

DegefaTamrat, Lemma Alemayehu,TegegneAzage, and Youngs, Curtis R. 2016. "Superovulation of Boran Cattle in Ethiopia: A Preliminary Report,"Animal Industry Report: AS 662, ASL R3067. Available at: http://lib.dr.iastate.edu/ans_air/vol662/iss $1 / 28$

Demissu, H., Fekadu, B. and Gemeda, D. 2014. Dairy Productive Potential, Challenges and Production opportunities of Horro and their F1 Jersey Crossbred Cows A Case of Guduru Livestock production and Research Center and Its Surroundings, West Oromia, Ethiopia. Science, Technology and Arts Research Journal.3(4).79-84.

Desalegn Gebremedhin. 2008. Assessment of problems/constraints associated with artificial insemination service in Ethiopia.MSc thesis, Addis Ababa University, Ethiopia.

Desalegn, G/Medhin, MergaBekana, AzageTegegne and KelayBelihu. 2009. Status of artificial insemination service in Ethiopia. In: The 17th Annual Conference of the Ethiopian Society of Animal Production (ESAP), Sept 24-26, 2009 Addis Ababa, Ethiopia, 87-104.

Desta Kelay, 2002. Analyses of Dairy Cattle Breeding Practices in Selected Areas of Ethiopia. PhD thesis, Humboldt-Universitätzu Berlin, Germany.

DuPonte, M. W. 2007. The Basics of Heat (Estrus) detection in cattle, cooperative extension service, Collage of Tropical Agriculture and Human resources, University of Hawai at manoa, livestock management LM-15. $<$ http://www.ctahr.Hawaii.edu/freepubs >. September 4, 2014.

EmebetMureda and ZelekeMekuriaw, Z. 2007. Reproductive Performance of Crossbred Dairy Cows in Eastern lowlands of Ethiopia. Livestock Research for Rural Development.19 (161)

Engidawork, B. 2012.Evaluation of artificial insemination service efficiency and reproductive performance of crossbred dairy cows in north shewa zone Ethiopia, M.Sc. Thesis approved by Haramaya University, Ethiopia.

Eijkel, T.C.J. and Berg, D.V.A. (2005). Nanofluidics: what is it and what can we expect from it?.Microfluid Nanofluid, 1:249-267.

FAO (Food and agriculture organization of the UN). 2007. The state of the world ${ }^{\text {ee }}$ s animal genetic resources for food and agriculture. B. Rischkowsky and D. Pilling, eds. Rome. [www.fao.org/docrep/010/a1250e/a1250e00.htm].

FAO (Food and agriculture organization), 2008. Training manual for embryo transfer in cattle.

FAO (Food and agriculture organization), 2011. Annual Production Yearbook, FAO, Rome.

FedluHassen, EndashawBekele, WorknehAyalew and TadelleDessie, 2007. Genetic variability of five indigenous Ethiopian cattle breeds using RAPD markers.African journal of biotechnology.6 (19)22742279. Retrieved January 10, 2012, from http://www.academic jounals.org/AJB

Fikre Lamu. 2007. Reproductive and lactation performance of dairy cattle in the Oromia Central highlands of Ethiopia with special emphasis on pregnancy period, Doctoral thesis Submitted to Department of Clinical Sciences, Swedish University of Agricultural Sciences.

Garner, D.L. 2006. Flow cytometric sexing of mammalian sperm. Theriogenology; 65: 943-957. 
Gebrekidan, T.W., Zeleke M.Z. and Gangwar S.K. 2012 Reproductive and productive performance of dairy Cattle in central zone of Tigray, Northern Ethiopia.

GebreMedhin, D. 2005. All in one: A Practical Guide to Dairy Farming. Agri-Service Ethiopia Printing Unit, Addis Ababa, pp: 15-21.

Girmay, G. Berihanu, G. and Bahlibi, W. 2015. The Effect of One Shot Prostaglandin on Estrus synchronization of Local and Holstein Fresian Cattle in and around WukrokilteAwulaelo District, Northern Ethiopia. Journal of Biology, Agricultural and Healthcare, 5.7.

Gupta J., Laxmi A., Vir Singh O. and Ashutosh. 2008. A comparative study on evaluation of three synchronization protocols at field level in both cattle and buffaloes. 20 (175).

Haileyesus, A. 2006. Evaluation of artificial insemination service efficiency and reproductive performance of Friesian crosses North Gondar Zone, MSc Thesis, Alemaya University Ethiopia.

Hamid, J. 2012. Study on Factors Affecting the Success of Artificial Insemination Program

Hansen, G.R., 2006. Managing Bull Fertility in Beef Cattle Herds Animal Science. Department Florida Cooperative, Extension, Service, Institute of Food and Agricultural Sciences, University of Florida. http://edis.ifas.ufl.edu Health and Prod. 35. 551-561.

Heyman, Y. 2005. Nuclear transfer: A new tool for reproductive biotechnology in cattle. ReprodNutrDev 45: 353 -361 .

Holm, D.E., Thompson P.N. and Irons P.C. 2008. The economic effects of an estrus synchronization protocol using prostaglandin in beef heifers. Theriogenology, 70.1507-1515.

Islam, R. 2011. Synchronization of estrus in cattle: A review. Veterinary World 4:136141 Available at: www.veterinaryworld.orgAccessed on Oct 28.

Kahi, A. 2002.Crossbreeding systems and appropriate levels of exotic blood: examples from kilifi plantations.

KefyalewAlemayehu and Addis Getu, 2015. The Status of Estrus Synchronization and Conception Ratein Ethiopian Cattle Breed International Journal of Agriculture and Veterinary Sciences.

Kumar, N., Yemane, A., Berihu, G. and Yohannes, H. 2014. Productive and Reproductive Performance of Local Cows under Farmer's Management in and around Mekelle Ethiopia IOSR Journal of Agriculture and Veterinary Science, Volume 7, Issue 5 Ver. III. PP 21-24.

Kuster,CE.,singer ,KS,Althouse,G.C.2004.determining sample size for the morphological assessment of sperm theriogenology 61:691-703.

Lamb, G. Cliff, 2010. Estrus Synchronization protocols for cows, North Florida Research and Education Center, Marianna, Florida. Proceedings, Applied Reproductive Strategies in Beef Cattle 28-29.

Larsen J.E lamb, G.C., Stevenson, J.S., Jhonson, S.K,Day ,M.L, Geary,T.W,Kesler,Dejornette , J.M,Sctrick,F.W,Dicostanzo,A. And arsenvo J.O, 2006.Synchronization of etrus insemination and timed or artificial insemination using gonadotropin hormone prostaglandin Fand progestronJ animal scie 84; 332-342.

Lobago, F. 2007. Reproductive and Lactation Performance of Dairy Cattle in the Oromia Central Highlands of Ethiopia with Special Emphasis on Pregnancy Period Doctoral thesis, Swedish University of Agricultural Sciences, Uppsala.

Lonny, W. 2010. Livestock initiative Morell Agro industries, PLC, Sowng hope and prosperity www.morrellagro.com accessed January, 2015, 34.

Madan, M.L, 2005. Animal biotechnology: applications and economic implications in developing countries. Rev Sci Tech off IntEpitz; 24(1): 127-139.

Mapletoft, R.J. (2013). History and perspectives on bovine embryo transfer. Anim. Reprod., 10:168-173.

McEvoy, T. G., Alink, F. M., Moreira, V. C., Watt, R. G., Powell, K. A., Greve, T. and Callesen, H. 2006. Embryo technologies and animal health - consequences for the animal following ovum pick- up, in vitro embryo production and somatic cell nuclear transfer Theriogenology, 926- 942.

Mekonnen A., Haile A., Dessie T. and Mekasha, Y. 2012. On farm characterization of Horro cattle breed production systems in western Oromia, Ethiopia. Livestock Research for Development 24(100) Retrieve June 25, 2015 from http.//www.irrd.org/lrrd24/6/meko24100htm.

Melku, M. 2016. Milk production and reproductive performance of local and crossbreed dairy cows in selected districts of west gojam zone, amhara region, MSc Thesis, Bahir Dar University Ethiopia,

Menale, M., Mekuriaw, Z., Mekuriaw, G. and Taye, M. 2011.Reproductive performance of Fogera cattle at Metekel Cattle Breeding and Multiplication Ranch, North West Ethiopia.Journal of Animal and Feed Research, 1(3).99-106.

Mgongo, F.O., Mujuni K, P. and Kitambi P. 2008. Pregnancy rates of crossbred dairy cattle synchronized using GnRH and one injections of PGF2 versus two injections of PGF2 prior to insemination. Journal of Livestock Research and Development.21 (8).

Miah A.G., Salma U. and Hossain M.M. 2004.Factors Influencing conception rate of local and crossbred cows in Bangladesh,International Journal of Agriculture and Biology, 6(5), 797- 801.Michael, L. D. and Thomas, W.G. 2005. Hand book of estrous synchronization. The Ohio State University, Ohio Agricultural Research 
and Development Center, Ohio. Western Region Publication 14:1-41.

More money, milk and meat: Promoting mass artificial insemination for Ethiopian cattle, 2014 (video file), Available from: <https://youtu.be/TgAbC2v0zKo> [7 July 2015].

Mukassa-Mugerwa E., Tegegn A. Mattoin M., and Cecchini G. (1989): Effect of EstrusSynchronization with Prostaglandin F2 $\alpha$ in Ethiopian Highland Zebu (Bosindicus) cows. Animal Production 48:367-373.

Murugavel K., Yanize J.K., Santolaria, M., Lopez, B. And Lopez-Gatius, F. 2010. Prostaglandin based estrus synchronization in Post-Partum dairy cows. An update.The international Journal of Applied Research in Veterinary Medicine. AIC, 2011. National Artificial Insemination Center (NAIC) Annual Report, 2011.

Nibret, M. 2012. Study on Reproductive Performance of Crossbred Dairy Cows under Small Holder Conditions in and Around Gondar, North Western Ethiopia. Journal of Reproduction and Infertility

Păcală, N., Bencsik, I., Dronca, D., Acatincăi, S., Petroman, I., Cornelia, P., Ada, C., Carabă, I., Alexandra and B. and Papp, S. 2009. Researches regarding the effect of PGF2 $\alpha$ administration interval on cow's estrus synchronization Banat's University of Agricultural Science and Veterinary Medicine, Timisoara 54:258-260.

Patterson, D. J. Mallory, D. A. Nash, J. M. Martin, N. T. and Smith, M. F. 2011. Strategies to optimize use of AI in cow/calf production systems: focus on fixed-time AI protocols for cows Proceedings, Applied Reproductive Strategies in Beef Cattle - Northwest, September 30 -October 1, 2011; Boise, ID, USA.

Pennington, A.J., 2013. Heat Detection in Dairy Cattle FSA4004, University of Arkansas Division of Agriculture Web United States Department of Agriculture, National Institute of Food and Agriculture.

Perry, G.A., Dalton, J.C and Geary, T.W. 2010.Management Factors Influencung fertility in Synchronized and Natural Breeding Program Applied Reproductive strategies conference proceedings August 5th and 6th.Printing Unit, Addis Ababa. Pp. 15-21.

Quintela, LA., Pena AI., Taboada M.J, Alonso G., Varela Portas B., Diaz C., Barrio M., Garcia M.E, Becerra J.J. and Herradon P.G. 2004. Risk Factors for Low Pregnancy Rate in Dairy Cattle.A Retrospective Study in the North West of Spain.Archivos de Zootecnia 53. 69-76.

Rajesh Wakchaure, SubhaGanguly, Parveez Ahmad Para, Praveen Kumar Praveen and KausarQadri, 2015. Relevance and Technological Implications of in Vitro Fertilization in Animal Breeding and Reproduction: A Review Volume 5, Issue 11

Rath, D. 2008. Status of sperm sexing technologies Proceedings of the 24th scientific meeting of the European embryo transfer association, Pau, France, 12-13, September. [www.aete.eu /pdf publication/24.pdf].

Reolofs, 2010. Knowledge of estrus behavior and the estrus to ovulation interval is essential for estimating the best time to artificially inseminated cattle.

Rick, R. and Gene, D. 2013. Synchronizing Estrus in Beef Cattle, University of Nebraska-Lincoln Lincoln, NE 68588 | 402-472-7211.

Ross, Wilson, 1992. Maffra Secondary College Embryo Transfer in Cattle.

Schmidt, M. 2007. Perinatal death associated with ET, IVP and cloning in cattle. Act aVeterinariaScandinavica, 49 (Suppl. 1): S13.

Selk, G. 2013. Embryo Transfer in Cattle DASNR 102 Agriculture Hall, Oklahoma State University Stillwater, OK 74078, ANSI-3158, http://osufacts.okstate.edu

Shiferaw, Y. Tenhagen B. A., Bekana M. and Kassa, T. 2003. Reproductive performance of Dairy Cows Artificially Inseminated during Natural Heat and by Synchronization in FogeraWoreda, North-West of Ethiopia, African Journal of Basic and Applied Science

Soetan, K.O. 2008. Agricultural Biotechnology: The Solution to the Problem of Global Food Crisis. Proceedings 1st International Society for Biotechnology Conference (ISBT, 2008) held at Sikkim Mannipal Institute of Science and Technology, Majitar, Sikkim, India on December 28-30,

TadesseGugssa, 2015.Effects of prostaglandin administration frequency, artificial insemination timing and breed on fertility of cows and heifers in eastern zone of Tigray region, MSc Thesis, Mekelle University Ethiopia.

Tadesse, A., Zeleke, M. and Berhanu, B. 2014.Status and constraints evaluation of artificial insemination in cattle in the three selected districts of Western Gojjam Zone; Amhara Region, Ethiopia.African Journal of animal production and Husbandary 1(2), pp.020-028.

Tamrat Degefa, Alemayehu, Lemma, AzageTegegne and Curtis R. Young, 2016. Superovulation of Boran Cattle in Ethiopia: A Preliminary Report Iowa State University Animal Industry Report.

TegenuGizaw, FeyeraGemedaDima, 2016.Assessment of problems and constraints associated with artificial insemination service in the two selected districts of arsi zone Journal Of Harmonized Research in Medical and Health Sci.3(1) 14-37.

Thibier, M. 2005. Significant increases in transfers of both in vivo derived and in vitro produced embryos in cattle and contrasted trends in other species In IETS Newsletter; 23(4): 11-17.

Tropentag, 2012.Göttingen "Resilience of agricultural systems against crises.IPMS Experience with hormonal oestrus synchronization and mass insemination in Ethiopia. September, 19-21,

Webb, D.W. 2003.Artificial Insemination in Cattle, University of Florida, Gainesville. IFAS Extension,; DS 58: 1 
- 4. 44.

Woreda, North-West of Ethiopia. African Journal of Basic and Applied Science 7(5).291-297.

ZelalemYilma., G.B., EmmannuelleGuernebleich and AmehaSebsibe. 2011. A Review of the Ethiopian Dairy Sector. Ed. Rudolf Fombad, Food and Agriculture Organization of the United Nations, Sub Regional Office for Eastern Africa (FAO/SFE), Addis Ababa, Ethiopia, pp 81.

Zewde, E. (2007): Artificial insemination and its implementation. Ethiopian Society of Animal Production (ESAP). Addis Ababa, Ethiopia. Pp. 7-14, 29, 45. 